\title{
Radial access during percutaneous interventions in patients with acute coronary syndromes: should we routinely monitor radial artery patency by ultrasonography promptly after the procedure and in long-term observation?
}

\author{
Anna Lisowska $\cdot$ Małgorzata Knapp $\cdot$ Agnieszka Tycińska $\cdot$ \\ Piotr Sielatycki • Robert Sawicki • Paweł Kralisz • \\ Włodzimierz J. Musiał
}

Received: 2 June 2014 / Accepted: 9 August 2014/Published online: 22 August 2014

(c) The Author(s) 2014. This article is published with open access at Springerlink.com

\begin{abstract}
Access-site vascular complications in patients undergoing transradial coronary procedures are rare but may have relevant clinical consequences. The aim of the study was to evaluate: (1) radial artery's (RA) patency immediately after the procedure and in long-term observation, (2) factors influencing the frequency of radial artery's occlusion (RAO) after percutaneous coronary intervention $(\mathrm{PCI})$ procedures performed via transradial access in the group of 220 patients with acute coronary syndromes (ACS). RA ultrasound was performed 48-72 h after the procedure and in those who were diagnosed with RAO-again after 6-12 months. According to the ultrasonographic findings, the patients were divided into two subgroups: 187 pts ( $85 \%)$ with patent RA after PCI and 33 pts (15\%) with RAO. Both sub-groups significantly statistically differed with regard to the frequency of local hematomas-15 versus $27.3 \%(p=0.02)$, the frequency of applying IIbIIIa inhibitors in PCI-6.4 versus $15.1 \%$ $(p=0.015)$ and procedure duration-0.59 \pm 0.37 versus $0.77 \pm 0.38(p=0.014)$, respectively. In a multifactorial analysis the only factor influencing RA patency promptly after the procedure was PCI duration $(p<0.05, \mathrm{r}=$ $-0.22)$. In the follow-up, right RA remained still obstructed in 28 patients $(12.7 \%)$ whereas in five patients $(2.3 \%)$ the regular flow in RA was resumed. The chronic RAO was clinically silent. Due to insignificant frequency of the
\end{abstract}

A. Lisowska $(\bowtie) \cdot$ M. Knapp · A. Tycińska · P. Sielatycki ·

R. Sawicki · W. J. Musiał

Departament of Cardiology, Medical University of Bialystok,

Ul. Skłodowskiej 24A, 15-276 Białystok, Poland

e-mail: anlila@poczta.onet.pl

P. Kralisz

Department of Invasive Cardiology, Medical University of Bialystok, Ul. Skłodowskiej 24A, 15-276 Białystok, Poland occurrence of RAO after PCI procedure in patients with ACS as well as practically lack of clinical consequences of this artery's occlusion in long-term observation, we do not see any implications to routine ultrasound periprocedural RA evaluation.

Keywords Radial access - Radial artery occlusion · Ultrasonography

\section{Introduction}

The entry site complications associated with artery cannulation during coronary angiographies and percutaneous coronary interventions (PCIs) delay discharge and require additional procedures. Radial and femoral approaches are both safe and effective for PCI. However, the lower rate of local vascular complications may be a reason to use the radial approach [1]. The transradial approach for percutaneous coronary intervention and angiography has been shown to be safe and effective alternative to the traditional transfemoral approach. Transradial PCI has been shown to reduce access site-related bleeding complications compared with procedures performed through a femoral approach. Used extensively throughout Europe for the past 15 years, this technique has been recently recommended accordingly to ESC guidelines. Lower direct costs, fewer vascular complications, better patient acceptance and earlier ambulation are some of the direct benefits from using radial access [2]. Access-site vascular complications in patients undergoing transradial coronary procedures are rare but may have relevant clinical consequences [3]. These can be: spasm, occlusion or perforation of radial artery (RA), hematoma, pseudoaneurysm, arteriovenous fistula, nerve injury [4]. The most common complication is 
Table 1 Clinical characteristic of study group

\begin{tabular}{lllll}
\hline & $\begin{array}{l}\text { Whole study } \\
\text { group }(\mathrm{n}=220)\end{array}$ & $\begin{array}{l}\text { Patients with patent radial } \\
\text { artery after PCI }(\mathrm{n}=187)\end{array}$ & $\begin{array}{l}\text { Patients with occluded radial } \\
\text { artery after PCI }(\mathrm{n}=33)\end{array}$ & $\begin{array}{l}\mathrm{p} \text { (pts with patent versus } \\
\text { occluded radial artery) }\end{array}$ \\
\hline Age $(\mathrm{y})$ & $64.0 \pm 12.2$ & $64.0 \pm 11.9$ & $63.4 \pm 13.5$ & NS \\
Men & $167(75.6 \%)$ & $147(78.6 \%)$ & $20(60.6 \%)$ & $\mathrm{p}=0.025$ \\
STEMI & $133(60.2 \%)$ & $110(58.8 \%)$ & $17(51.5 \%)$ & NS \\
NSTEMI & $88(39.8 \%)$ & $71(38.0 \%)$ & $14(42.4 \%)$ & NS \\
EF $(\%)$ & $46.7 \pm 9.7$ & $46.9 \pm 9.2$ & $45.7 \pm 12.4$ & NS \\
Creatinine $(\mu \mathrm{mol} / \mathrm{l})$ & $122.8 \pm 21.0$ & $130.8 \pm 53.0$ & $76.9 \pm 21.2$ & $p=0.04$ \\
Total cholesterol $(\mathrm{mmol} / \mathrm{l})$ & $4.7 \pm 1.1$ & $4.6 \pm 1.1$ & $5.0 \pm 1.25$ & $\mathrm{NS}$ \\
LDL-cholesterol $(\mathrm{mmol} / \mathrm{l})$ & $3.0 \pm 1.0$ & $2.9 \pm 1.0$ & $3.3 \pm 1.1$ & $\mathrm{NS}$ \\
HDL-cholesterol $(\mathrm{mmol} / \mathrm{l})$ & $1.1 \pm 0.3$ & $1.1 \pm 0.35$ & $1.1 \pm 0.3$ & $\mathrm{NS}$ \\
Glucose $(\mathrm{mmol} / \mathrm{l})$ & $6.3 \pm 1.8$ & $6.4 \pm 1.8$ & $6.2 \pm 1.2$ & $\mathrm{NS}$ \\
\hline
\end{tabular}

asymptomatic RA occlusion, which rarely leads to clinical events, owing to the dual collateral perfusion of the hand. RA spasm is relatively common and can result in access and procedural failure. RA perforation can lead to severe forearm hematoma and compartment syndrome. Pseudoaneurym and arteriovenous fistula are rare complications, which can likely be managed conservatively without surgical intervention. Nerve injury occurring during access has been reported, although symptoms usually improve over time [4].

The aim of the study was to evaluate: (1) RA's patency immediately after the procedure and in long-term observation as well as the consequences of RA's chronic obstruction, (2) factors influencing the frequency of RA obstruction after PCI procedures performed via transradial access in the group of patients suffering from acute coronary syndromes (ACS).

\section{Methods}

Selection of the study population

The study comprised consecutive patients with ACS (STEMI and NSTEMI) who were hospitalized in Department of Cardiology in years 2010-2012 and underwent invasive procedures: coronary angiography and angioplasty via RA access. The inclusion criteria were: age between 18 and 80 years, a completed coronary angiography and doppler ultrasound examination of the RA. Selected clinical and biochemical risk factors of atherosclerosis progression were assessed. Following the above criteria, 220 patients were enrolled. According to the ultrasonographic findings, patients were divided into two sub-groups: 187 pts with patent RA after PCI and 33 pts with occluded RA after PCI. Detailed clinical and procedural characteristics of these groups are given in Tables 1 and 2.

\section{Coronary angiography}

PCIs were performed in the course of ACS. During coronary angiography $6 \mathrm{~F}$ catheter was used. PCIs were routinely performed via right RA. The patients who underwent the procedure via femoral artery for technical reasons were excluded from the study. Before the procedure, all the patients had performed Allen test and received standard antiplatelet treatment (acetylsalicylic acid and clopidogrel) in loading doses. As a rule, RA puncture and vascular sheath insertion are followed by injection of verapamil $(2.5 \mathrm{mg}$ diluted in $2 \mathrm{ml}$ of $0.9 \% \mathrm{NaCl}$ ) and 5,000 U unfractionated heparin (UFH). During PCI ACT was controlled (300 s) and additional UFH was added if needed. Platelet glycoprotein IIb/IIIa receptor antagonists were used according to the operator's decision. After the procedure and vascular sheath removal, as a rule, compression with a tourniquet (SUNMED ${ }^{\mathrm{TM}}$ Disposable TR-Closure Band, As Medical, Netherlands) was applied followed by 4-6-h. Experienced operators were highly experimented in radial access $(>80 \%$ of their procedures routinely performed by radial access during the past 2 years) and high volume operators ( $>100$ procedures per year).

Doppler ultrasonography of the radial arteries

Radial artery ultrasound was routinely performed in the second or third day after the procedure, independently on the access site complcations. Philips iE 33 ultrasound equipment with a $3-11 \mathrm{MHz}$ linear transducer was used. Blood flow was assessed with colour-Doppler sonography in 2D images. The flow in both right and left RA was studied. The nonintervened left RA served as the control. Next in the group of patients who were diagnosed with periprocedural right RA obstruction the ultrasound control test was performed again after the lapse of app. 6-12 months. 
Table 2 Procedural characteristic of study group

\begin{tabular}{|c|c|c|c|c|}
\hline & $\begin{array}{l}\text { Whole study } \\
\text { group }(n=220)\end{array}$ & $\begin{array}{l}\text { Patients with patent radial } \\
\text { artery after PCI }(n=187)\end{array}$ & $\begin{array}{l}\text { Patients with occluded radial } \\
\text { artery after PCI }(n=33)\end{array}$ & $\begin{array}{l}p \text { (pts with patent versus } \\
\text { occluded radial artery) }\end{array}$ \\
\hline \multicolumn{5}{|l|}{ Angiographically } \\
\hline 1-vessel disease & $106(47.9 \%)$ & $94(50.3 \%)$ & $15(45.5 \%)$ & \multirow[t]{3}{*}{ NS } \\
\hline 2-vessel disease & $63(28.5 \%)$ & $55(29.4 \%)$ & $11(33.3 \%)$ & \\
\hline 3-vessel disease & $45(20.4 \%)$ & $38(20.3 \%)$ & $7(21.2 \%)$ & \\
\hline PCI LAD & $100(45.5 \%)$ & $83(44.4 \%)$ & $15(45.4 \%)$ & NS \\
\hline PCI RCA & $68(30.9 \%)$ & $56(30.0 \%)$ & $12(36.3 \%)$ & NS \\
\hline PCI Cx & $52(23.6 \%)$ & $48(25.7 \%)$ & $6(18.2 \%)$ & NS \\
\hline Stent (number of pts) & $204(92.7 \%)$ & $173(92.5 \%)$ & $31(93.9 \%)$ & NS \\
\hline \multicolumn{5}{|l|}{ Number of patients with } \\
\hline 1 stent & $149(73.0 \%)$ & $125(72.5 \%)$ & $24(77.4 \%)$ & \multirow[t]{3}{*}{ NS } \\
\hline 2 stents & $51(25 \%)$ & $45(26.0 \%)$ & $6(19.4 \%)$ & \\
\hline 3 stents & $4(2.0 \%)$ & $3(1.7 \%)$ & $1(3.2 \%)$ & \\
\hline BMS (number of pts) & $167(81.8 \%)$ & $143(82.6 \%)$ & $24(77.4 \%)$ & NS \\
\hline DES (number of pts) & $37(18.1 \%)$ & $30(17.3 \%)$ & $7(22.6 \%)$ & NS \\
\hline $\begin{array}{l}\text { Flow velocity in the right } \\
\text { radial artery }(\mathrm{cm} / \mathrm{s})\end{array}$ & & $60.7 \pm 19.2$ & 0 & \\
\hline $\begin{array}{l}\text { Flow velocity in the left } \\
\text { radial artery }(\mathrm{cm} / \mathrm{s})\end{array}$ & $62.8 \pm 19.2$ & $63.0 \pm 17.4$ & $62.1 \pm 27.7$ & NS \\
\hline Local hematoma & & $28(15.0 \%)$ & $9(27.3 \%)$ & $p=0.02$ \\
\hline Dose of heparin during PCI & $5.85 \pm 2.25$ & $5.88 \pm 2.26$ & $5.64 \pm 2,18$ & NS \\
\hline Blocker GP IIbIIIa during PCI & $17(7.7 \%)$ & $12(6.4 \%)$ & $5(15.1 \%)$ & $p=0.015$ \\
\hline PCI duration (hours) & $0.62 \pm 0.37$ & $0.59 \pm 0.37$ & $0.77 \pm 0.38$ & $p=0.014$ \\
\hline Previously PCI via radial artery & $13(5.9 \%)$ & $11(5.9 \%)$ & $2(6.1 \%)$ & NS \\
\hline
\end{tabular}

\section{Statistical analysis}

The mean values and standard deviations for quantitative variables were calculated as well as the quantitative and percentage distribution for qualitative variables. Pearson's correlation coefficient was calculated for categorical variables of normal distribution and Spearman's correlation coefficient for variables not satisfying normal distribution criteria. To compare the groups, the statistical analysis for variables of normal distribution estimated using the Kołomogorow compatibility test was carried out using the unpaired Student's test and the Mann-Whitney test for variables inconsistent with a normal distribution. A comparison of qualitative variables between the groups was performed using the $\chi^{2}$ test. A $p$ value of $<0.05$ was considered statistically significant.

The statistical analysis was carried out using Statistica 10.0 PL software.

\section{Results}

Detailed characteristics of the studied group is presented in Tables 1 and 2. According to the ultrasonographic findings, the patients were divided into two sub-groups: 187 pts (85\%) with patent RA after PCI and 33 pts (15\%) with occluded RA after PCI. The patients in both groups did not differ significantly with regard to age, the frequency of STEMI/NSTEMI occurrence, concentration of total, LDL and HDL cholesterol and glucose or a magnitude of ejection fraction assessed echocardiographically. In the group of patients with occluded RA, creatinine concentration was lower, and more often these were female patients.

As far as procedural and periprocedural characteristics of the studied group is concerned, there were no statistically significant differences between the sub-groups in the scope of: a degree of advancement of atherosclerotic changes in coronary arteries, the localization of the lesions, a number of implanted stents, a type of applied stent (BMS vs DES), a dose of heparin applied in the procedure, and a number of previously performed PCI via transradial approach. On the other hand, both sub-groups significantly statistically differed with regard to the frequency of the occurrence of local hematomas-27.3\% in pts with occluded RA versus $15.0 \%$ in pts with patent RA after PCI $(p=0.02)$, the frequency of applying IIbIIIa inhibitors during PCI$15.1 \%$ versus $6.4 \%(p=0.015)$ and procedure duration$0.77 \pm 0.38$ versus $0.59 \pm 0.37(p=0.014)$, respectively. 
None of the patients required local surgical intervention. Conservative management including local compression allows successful management in all cases of local complications. After the performance of a multifactorial analysis, it appeared that the only factor influencing RA patency promptly after the procedure is PCI duration $(p<0.05, \mathrm{r}=-0.22)$.

\section{Follow-up}

The follow-up period amounted to 6-12 months. In 33 (15\% of whole group) patients who were diagnosed with periprocedural obstruction of right RA, after the follow-up period the right RA remained still obstructed in 28 patients $(12.7 \%)$ whereas in 5 patients $(2.3 \%)$ a regular flow in the RA was resumed. In the group of patients with persistent obstruction of RA, only one patient exhibited a mild neurological hand deficit in the follow-up (right arm's coldness, periodic paraesthesia). The resumption of RA patency correlated statistically significantly with PCI procedure duration $(p<0.05, r=-0.17)$.

\section{Discussion}

Transradial approach to coronary angiography is a progressive and increasingly more often used technique. RA access is associated with lower risk of any complications or access site bleeding complications. Use of the RA for primary or rescue $\mathrm{PCI}$ is associated with improved clinical outcomes [5]. Apart from its advantages, it is important to remember four important issues related to transradial procedures: (1) radial access site bleeding, (2) RA injury and occlusion, (3) radiation exposure, and (4) implementation of a successful transradial primary percutaneous coronary intervention [6]. The most common complication is RA occlusion, which rarely leads to clinical events, owing to the dual collateral perfusion of the hand. In our own studies performed straight after the procedure, RA obstruction was found in $15 \%$ patients, which was asymptomatic in almost all patients, i.e. except one patient. RA occlusion (RAO) represents the most serious drawback-usual with an incidence of $4-12 \%$ in the literature [7-10]. Slightly higher incidence of early RAO in our study may be due to the fact that in all cases, PCI were performed in the course of ACS, these procedures were not planned. Moreover, in the most studies cited above, the presence of flow in the RA after the procedure was evaluated clinically [7-9], and in just a few [10]—ultrasound examination was performed, as in our population. Re-canalization of an iatrogenic RAO, although asymptomatic in the majority of cases, remains a discussed and challenging topic [11]. It is postulated that appropriate compression techniques and smaller sheath size can minimize the risk of RA occlusion [4]. In our centre during angiography $6 \mathrm{~F}$ catheter was applied. After the procedure and vascular sheath removal, as a rule, compression with a tourniquet was applied followed by 4-6-h. During the follow-up in the studied group of patients RA remained still obstructed in $12.7 \%$ patients whereas in $2.3 \%$ patients a regular flow in RA was resumed. In the group of patients suffering from persistent RA obstruction only one patient exhibited a mild neurological hand deficit in the follow-up. The large proportion of late occlusion of the RA during the follow-up period of 6-12 months observed in our study population differs from the data available in the literature. Other researchers have observed a return flow in the initially occluded RA after 1 month at an average of $30-40 \%$ of patients [12, 13], and in our group of patients, this percentage was only $15 \%$. According to the authors' knowledge, there is no data concerning longer follow-up.

In our study, (after performance of a multifactorial analysis) it appeared that the only factor influencing RA patency promptly after the procedure was PCI duration. Hand ischemia with necrosis has never been reported in our study group, which is consistent with other authors' observations [4]. Although the RA is superficial and haemostasis can be achieved readily, access site bleeding can occur and can lead to forearm haematoma and, rarely, to compartment syndrome, if not managed promptly. In our study local hematomas occurred significantly more frequenlty in patients suffering from obstructed RA after the procedure. Nonetheless, no patient required local surgical intervention. Conservative management including local compression allows successful management in all cases of local complications. Pseudoaneurym and arteriovenous fistula are rare complications. Moreover, we found a case report of right RA perforation observed after successful stenting of left anterior descending artery through right radial access $[14,15]$. In the group of our patients we did not observe such type of complications.

The potential reduction in mortality seen with transradial primary PCI must be balanced against the clinical imperative of timely reperfusion. Operators and catheterization laboratories should not begin a transradial primary PCI programme until sufficient radial experience has been gained in the elective setting [6]. In our department PCIs were performed by experienced operators (highly experimented in radial access and high volume operators).

In the studied group of patients with occluded RA after PCI creatinine concentration was lower, and more often these were female patients. Other studied clinical and biochemical parametres appeared insignificant. It appeared in other authors' studies that age, sheath size, the dose of heparin were significantly higher in patients with than without bleeding complications. However, body mass 
index (BMI) was significantly lower in patients with than without bleeding complications [16]. Sheath size was significantly higher in patients with than without RA occlusion [16]. In our study during coronary angiography $6 \mathrm{~F}$ catheter was used in all patients. Multiple logistic analysis revealed that the only factor influencing RA patency promptly after the procedure was its duration.

Right and left radial approaches are feasible and effective to perform percutaneous procedures. However, the left radial route is associated with shorter procedures and lower radiologic exposure than the right radial approach, independently of an operator's proficiency [17]. In our study PCIs were routinely performed via right RA. Left RA was left intact with a view of a possible use of this artery as a bridge in case the patient qualifies for Coronary Artery Bypass Graft procedure in the future. We should remember that a marked narrowing in the diameter of the intervened RA and impaired FMD response indicating endothelial dysfunction were observed at a mean of 9 months after transradial intervention. Structural and functional changes should be taken into consideration if previously intervened RA would be used for interventions, such as arterial bypass graft or dialysis fistula [18].

In our study group there were no significant differences in spite of a higher incidence of radial artery occlusion (RAO) in patients with previously performed PCI via transradial approach. Moreover, similar results were obtained by other researchers [19].

A sterile inflammatory reaction at the radial access site has been described in the literature as an adverse local reaction to Cook hydrophilic coated sheaths during transradial catheterization. Until now, this reaction has not been observed with non-Cook hydrophilic sheaths [20]. In our cathlab non-Cook hydrophilic sheaths are applied-we did not observe any allergic reactions as well.

\section{Study limitations}

The main study limitation is small size of the study group.

\section{Conclusions}

Due to insignificant frequency of the occurrence of RA occlusion after PCI procedure in patients with ACS as well as practically lack of clinical consequences of this artery's occlusion in long-term observation, we do not see any implications to routine ultrasound periprocedural RA evaluation. Control ultrasonographic tests should be reserved solely to patients with a clinical picture that may suggest the incidence of local complications. The only factor influencing RA patency promptly after the procedure was PCI duration. Moreover, ultrasonographic and clinical control after 6-12 months after the procedure is not necessary because persisting obstruction of RA does not generate symptoms.

\section{Conflict of interest None.}

Open Access This article is distributed under the terms of the Creative Commons Attribution License which permits any use, distribution, and reproduction in any medium, provided the original author(s) and the source are credited.

\section{References}

1. Jolly SS, Yusuf S, Cairns J, Niemelä K, Xavier D, Widimsky P, Budaj A, Niemelä M, Valentin V, Lewis BS, Avezum A, Steg PG, Rao SV, Gao P, Afzal R, Joyner CD, Chrolavicius S, Mehta SR, RIVAL trial group (2011) Radial versus femoral access for coronary angiography and intervention in patients with acute coronary syndromes (RIVAL): a randomised, parallel group, multicentre trial. Lancet 377(9775):1409-1420

2. Schueler A, Black SR, Shay NJ (2013) Management of transradial access for coronary angiography. Cardiovasc Nurs 28(5):468-472

3. Burzotta F, Mariani L, Trani C, Coluccia V, Brancati MF, Porto I, Leone AM, Niccoli G, Tommasino A, Tinelli G, Mazzari MA, Mongiardo R, Snider F, Schiavoni G, Crea F (2013) Management and timing of access-site vascular complications occurring after trans-radial percutaneous coronary procedures. Int $\mathrm{J}$ Cardiol 167(5): 1973-1978

4. Kanei Y, Kwan T, Nakra NC, Liou M, Huang Y, Vales LL, Fox JT, Chen JP, Saito S (2011) Transradial cardiac catheterization: a review of access site complications. Catheter Cardiovasc Interv 78(6):840-846

5. Johnman C, Pell JP, Mackay DF, Behan M, Slack R, Oldroyd KG, Berry C (2012) Clinical outcomes following radial versus femoral artery access in primary or rescue percutaneous coronary intervention in Scotland: retrospective cohort study of 4534 patients. Heart 98(7):552-557

6. Rao SV, Bernat I, Bertrand OF (2012) Remaining challenges and opportunities for improvement in percutaneous transradial coronary procedures. Eur Heart J 33(20):2521-2526

7. Sanmartin M, Gomez M, Rumoroso JR, Sadaba M, Martinez M, Baz JA, Iniguez A (2007) Interruption of blood flow during compression and radial artery occlusion after transradial catheterization. Catheter Cardiovasc Interv 70:185-189

8. Pancholy S, Coppola J, Patel T, Roke-Thomas M (2008) Prevention of radial artery occlusion-patent hemostasis evaluation trial (PROPHET Study): a randomized comparison of traditional versus patency documented hemostasis after transradial catheterization. Catheter Cardiovasc Interv 72:335-340

9. Pancholy SB (2009) Impact of two different hemostatic devices on radial artery outcomes after transradial catheterization. J Invas Cardiol 21:101-104

10. Cubero JM, Lombardo J, Pedrosa C, Diaz-Bejarano D, Sanchez B, Fernandez V, Gomez C, Vazquez R, Molano FJ, Pastor LF (2009) Radial compression guided by mean artery pressure versus standard compression with a pneumatic device (RACOMAP). Catheter Cardiovasc Interv 73:467-472

11. Skvaril J, Kockova R, Danickova K, Sedlon P (2012) Chronic radial artery occlusion after transradial catheterization. Re-canalization via an ipsilateral ulnar artery. Acta Cardiol 67(3):367-370

12. Stella PR, Kiemeneji F, Laarman GJ, Odekerken D, Slagboom T, van der Wieken R (1997) Incidence and outcome of radial artery 
occlusion following transradial artery coronary angioplasty. Cathet Cardiovasc Diagn 40:156-158

13. MontAlverne Filho JR (2003) Comparative study of the use of diltiazem as an antispasmodic drug in coronary angiography via the transradial approach. Arq Bras Cardiol 81:59-63

14. Al-Sekaiti R, Ali M, Sallam M (2011) Radial artery perforation after coronary intervention: is there a role for covered coronary stent? Catheter Cardiovasc Interv 78(4):632-635

15. Jurga J, Nyman J, Tornvall P, Mannila MN, Svenarud P, van der Linden J, Sarkar N (2011) Cerebral microembolism during coronary angiography: a randomized comparison between femoral and radial arterial access. Stroke 42(5):1475-1477

16. Honda T, Fujimoto K, Miyao Y, Koga H, Hirata Y (2012) Access site-related complications after transradial catheterization can be reduced with smaller sheath size and statins. Cardiovasc Interv Ther 27(3):174-180

17. Pelliccia F, Trani C, Biondi-Zoccai GG, Nazzaro M, Berni A, Patti G, Patrizi R, Pironi B, Mazzarotto P, Gioffrè G, Speciale G,
Pristipino C (2012) Prospective Registry of Vascular Access in Interventions in Lazio Region (PREVAIL) Study Group : comparison of the feasibility and effectiveness of transradial coronary angiography via right versus left radial artery approaches (from the PREVAIL Study). Am J Cardiol 110(6):771-775

18. Okuyan H, Açikgoz SK, Tacoy G, Kocaman SA, Abaci A (2012) Effect of transradial coronary angiography procedure on vascular diameter and vasodilator functions in the access site. Angiology [Epub ahead of print]

19. Nie B, Zhou YJ, Yang Q, Cheng WJ, Wang ZJ, Wang JL (2012) Safety and feasibility of repeated percutaneous transradial coronary intervention in the same route. Chin Med J 125(2):221-225

20. Swaminathan RV, Wong SC (2011) Radial access site inflammatory reaction to a recently available hydrophilic coated sheath. Catheter Cardiovasc Interv 77(7):1050-1053 